\title{
Els nous paradigmes de la didàctica de la història a Alemanya
}

\author{
Feride Durna * \\ Judit Sabido-Codina **
}

Resum

El pas del segle XX al XXI ha promogut, especialment en les últimes dècades, un canvi social remarcable. La crisi econòmica i sociopolítica, el canvi climàtic, la immigració, les guerres, el neonacionalisme, entre d'altres, són alhora aspectes polítics i educatius. La didàctica de la història ha de fer front a aquests nous reptes $i$ ha de responsabilitzar-se com a disciplina científica. A l'article resumim els debats epistemològics que van dur a terme el grup de treball Geschichtsdidaktik theoretisch Arbeitskreis der Konferenz für Geschichtsdidaktik e.V el març del 2019. En aquests, diversos científics de l'àmbit van exposar les seves perspectives respecte d'aquest nou paradigma de les responsabilitats socials de la didàctica de la història. Reptes que han arribat a Espanya més tard, però que estan essent alguns dels principals nuclis de conflicte a l'actualitat.

\section{Paraules clau}

Didàctica de la història, consciència històrica, societat, responsabilitat social, Geschichtsdidaktik theoretisch Arbeitskreis der Konferenz für Geschichtsdidaktik e.V

\section{La didàctica de la història a Alemanya: la Konferenz für Geschichtsdidaktik i el grup de treball Geschichtsdidaktik theoretisch Arbeitskreis der Konferenz für Geschichtsdidaktik e.V}

La didàctica de la història a Alemanya s'organitza entorn del grup Konferenz für Geschichtsdidaktik $(K G D)^{1}$, la finalitat del qual és la promoció del desenvolupament científic de la didàctica de la història. KGD busca una comunicació entre els diferents nivells educatius, per tal que actuïn com a agents actius per al desenvolupament i/o per a la promoció de la didàctica de la història. Els membres del $K G D$, tanmateix, es reuneixen en diversos grups satèl-lits de l'organització —Arbeitskreis-, a l'interior dels quals es troba el Geschichtsdidaktik theoretisch Arbeitskreis der Konferenz für Geschichtsdidaktik e.V.

Aquest grup es reuneix a Alemanya anualment per discutir sobre problemàtiques actuals de la disciplina. Per exemple, el canvi climàtic, el neonacionalisme, la identitat, entre d'altres. Els seus objectius són molt diversos i s'orienten cap a la didàctica de la història i l'actualitat. En concret, el 2019 el grup es va congregar a la Universitat de Colònia per

\footnotetext{
${ }^{*}$ ) Doctoranda de la Universitat de Barcelona. Philosophie/Ethik und Geschichte Mittlere/Neuere (Staatsexamen) per la Universitat de Heidelberg. Adreces electròniques: fdurnadu9@alumnes.ub.edu/ i fedurna@gmail.com

$\left(^{* *}\right)$ Professora associada de la Universitat de Vic, tècnica en recerca per la Universitat de Barcelona i membre del grup d'investigació i d'innovació consolidat i finançat DHIGECS (2017-SGR-426) - (GINDO-UB/161). Adreça electrònica: judit.sabido@uvic.cat/jsabido@ub.edu

(1) Més informació, a la pàgina web oficial: https://www.historicum.net/kgd/.
} 
debatre sobre la responsabilitat de la didàctica de la història i la societat, sota el títol: Geschichtsdidaktik und gesellschaftliche Verantwortung.

Aquests dos conceptes — «didàctica de la història» $\mathbf{i}$ «societat»— encara no van de la mà i susciten diversos replantejaments pel futur de la disciplina, convertint-se en el nucli de les jornades. Els dos dies de debat (11 i 12 de març de 2019) es van estructurar en quatre panells amb els següents títols: 1) Gesellschaftlichkeit und Geschichtsdidaktik: Grundlegende Überlegungen (Sociabilitat i Didàctica de la història: consideracions bàsiques); 2) Gesellschaftliche Aufgaben der Geschichtsdidaktik? (Les tasques socials de la didàctica de la història?); 3) Was sind gesellschaftspolitische Aufgaben der Geschichtsdidaktik I? (Quines són les tasques sociopolítiques de la didàctica de la història I?), i 4) Was sind gesellschaftspolitische Aufgaben der Geschichtsdidaktik II? (Quines són les tasques sociopolítiques de la didàctica de la història II?).

Temàtiques que sorgeixen de la necessitat de definir els paràmetres d'aquesta disciplina com a agent actiu en la societat, i que serveix per afavorir la presa de consciència dels investigadors, educadors, teòrics, etc., de l'àmbit. Aquest text neix dels articles enviats al Workshop i de les discussions que en van sorgir. Així doncs, s'estructura d'acord amb l'organització de les jornades esmentades.

\section{Panell I. Sociabilitat i Didàctica de la Història: consideracions bàsi- ques}

En aquest panell hi van participar tres ponents: Thomas Martin Buck (,Veränderung" und "Veränderbarkeit": Geschichte als Gegenwarts-und Handlungswissenschaft); Philipp McLean (Die Verantwortung der Geschichtsdidaktik für eine mündigkeitsorientierte - historische-Bildung), i Michael Zech (Welchem didaktischen Konzept folgt der Geschichtsunterricht? Fünf Thesen). Els temes es van debatre successivament entre els diversos assistents a les jornades.

El debat s'inicià amb les aportacions de Buck (2019), qui exposa que gran part de l'alumnat té dubtes sobre la percepció i la comprensió de la història. Segons l'autor, el coneixement històric s'estructura a través d'elements del passat que necessiten de l'ús del patrimoni o de fonts primàries per reconstruir-lo. Sorgeix, així, un nexe entre passat i futur: «Geschichte ist Deutung der Vergangenheit aus der Perspektive der Gegenwart» (p. 1) [«La història és una interpretació del passat des d'una perspectiva del present». Per tant, la història i el coneixement històric estan directament vinculats a la vida actual i pragmàtica de les persones, i quan es trenca aquest vincle apareix una desafecció cap a l'assignatura d'Història.

La nova didàctica de la història ha de demostrar la utilitat d'aquesta disciplina per a la societat actual. Un paradigma nou que es planteja la comprensió de l'entorn i del medi ambient de forma històrica, i no a partir d'una acumulació memorística del saber (Sauer, 2006, citat a Buck, 2019). El coneixement històric és canviant i dinàmic, i l'alumnat hauria d'entendre que el coneixement del passat és modificable i, per tant, interpretable en funció de l'òptica a través de la qual s'analitza.

Tot ésser humà posseeix coneixement històric. Per exemple, veure un àlbum o tenir una experiència històrica implica un coneixement. I què significa «experiència»? Buck (2019) planteja que és un fet del passat que es debat en el present per anticipar el futur. 
L'orientació d'aquestes experiències del passat cap a un futur dona estructura a la nostra vida i una consciència històrica, segons el mateix autor.

Aquestes aportacions van generar dues preguntes encara subjectes a debat: són l'experiència biogràfica i l'aprenentatge històric el mateix? Es poden modificar consciències històriques del passat? Seguidament, la discussió es va centrar en les aportacions de McLean (2019). L'autor, des d'un vessant més filosòfic, reflexiona sobre la responsabilitat social de la didàctica de la història. Qui té aquesta responsabilitat? Per què serveix? McLean (2019) veu necessari el desenvolupament d'una normativa que expliqui per què serveix la didàctica de la història i quina és la seva responsabilitat. Una normativa que cal construir a partir de quatre determinants ${ }^{2}$.

Determinants que busquen la Mündigkeit -la majoria d'edat kantiana, exposada pel filòsof alemany a la pregunta Què és la II/Iustració? (1784)- com a objectiu principal en els processos de formació i educació. Quan un individu pot reflexionar sobre un mateix, és capaç de participar de forma autònoma en els processos de transformació politicosocial. Per tant, és necessari un altre objectiu: promoure l'autonomia pròpia. Així, per poder participar en aquests processos de canvi es necessita una autonomia pròpia i la Mündigkeit. Dos elements que no són donats i que s'han de produir. Per tant, és necessària la creació de nivells i de requisits socials i individuals per arribar a aquests dos objectius. Només així cada membre de la societat podrà formar les seves finalitats pròpies.

En concret, la didàctica de la història té com a objectiu afavorir que l'alumnat assoleixi la Mündigkeit. l, per tant, té un paper fonamental a la societat. No obstant això, el discurs de la didàctica està per sota de la seva limitació, ja que aquesta disciplina fa una interpretació dels fenòmens del passat i de la seva presència en el present. McLean (2019) considera que per sortir d'aquesta limitació, la didàctica de la història hauria d'utilitzar la metodologia crítica d'ideologia, creant nous debats i noves perspectives.

Per finalitzar el debat del panell I es van presentar les aportacions de Zech (2019). L'autor exposa diversos conceptes que s'haurien de seguir a l'aula en la matèria d'Història. Considera que aquesta disciplina ha de debatre conceptes actuals de la societat.

Concretament, fa referència a dos de socials i identitaris contradictoris: per una banda, aquell col-lectiu que aposta per un món canviant, per l'interculturalisme, el pluralisme, la tolerància, la democràcia i la humanitat, i que promou una autodeterminació individual i cultural; per altra banda, un col-lectiu que lluita per les normes definides, perquè les tradicions no surtin del seu marc social, i que aposta pel nacionalisme, el totalitarisme, l'autocràcia, la repressió i el fanatisme religiós.

Dues identitats extremes i contradictòries que s'han de tractar a l'escola. La història escolar no ha de situar-se per sota de les ideologies nacionals o dels col-lectius ideològics. Aquesta institució ha de potenciar la identitat individual per sobre de la col-lectiva (Zech, 2019).

(2) «1) Aus der Anforderung bzw. Dem Anspruch heraus, Aussagen über die Steuerung und Ziele von Bildungsprozessen zu treffen, welche durch historische Phänomene in Gang gebracht werden; 2) Aus der Anforderung, in einer demokratischen Gesellschaft Geschichte in einer spezifischen Weise zu vermitteln; 3) Aus der Selbstbestimmung der Geschichtsdidaktik al die, Wissenschaft vom Geschichtsbewusstsein in der Gesellschaft; 4) Den Anforderungen, die daraus resultieren, dass die Geschichtsdidaktik sich als Teil der Geschichtswissenschat versteht» (p. 1). 
Per tant, la didàctica de la història ha de prendre la decisió de formar una identitat individual o col-lectiva. La primera potencia valors humanitaris i de canvis, mentre que la segona aposta per una identitat nacional i critica la interculturalitat. Es vol ensenyar una consciència històrica autoreflexiva o una consciència identitària nacional?

La promoció d'una consciència dialògica és un requisit per crear identitats que no depenen d'un collectiu dintre d'un marc nacional. Es tracta de crear i de formar un pensament $\mathrm{i}$ un judici de valors comparatius a les competències analítiques que es treballen a l'escola, per tal que l'alumnat pugui construir el seu propi futur.

\section{Panell II. Les tasques socials de la didàctica de la història?}

El segon panell, que tracta sobre si la didàctica de la història té alguna tasca pendent amb la societat, estava compost per Andreas Hübner (Das Anthropozän unterrichten? Zur Diskussion um die gesellschaftliche Verantwortung der Geschichtsdidaktik), Franziska Rein (Ambiguitätstoleranz als Ziel?! Zur Verantwortung der Geschichtsdidaktik) i Urte Kocka (Was sind gesellschaftliche Aufgaben der Geschichtsdidaktik?).

El debat s'inicià amb les aportacions de Hübner (2019) entorn del concepte Anthropozän. De forma habitual, l'ensenyament de la història ha tractat problemes sobre la convivència humana i la seva continuïtat, sobre les seves conseqüències - com els conflictes de poder-i sobre la dominància — com les resolucions que hi havia o que hi haguessin pogut haver-. La narrativa i la seva significació a l'aula, així com l'actor principal, queden restringits en l'humà. Per tant, si la didàctica de la història té una visió antropocèntrica, com podrà iniciar accions i responsabilitzar-se amb la societat? Les darreres investigacions han mostrat que existeix una dependència mútua entre la naturalesa i els humans. Aquests últims s'han d'entendre com una part de la xarxa d'actors distribuïts pel món, fet que es pot estudiar a partir de l'Anthropozän (Hübner, 2019). Concepte que significa la comprensió de l'època geològica com un període on l'ésser humà —amb les seves accions, forces i cultures - és part del canvi de la naturalesa i de la seva formació diversa. És a dir, depenent de com actuem i de les forces que utilitzem, estarem formant i canviant el món.

Segons Chakrabarty (2011), les discussions i els debats sobre l'Anthropozän —com el canvi climàtic i les seves implicacions socials - es poden llegir com un conflicte sobre com l'expliquem, el tractem i l'escrivim. Des de la perspectiva de la didàctica de la història podem dir que és una temàtica que es troba en l'àmbit de les ciències naturals. No obstant, això és molt discutible atès que si mirem el desenvolupament de Praxis des Lernens i si intentem comprendre les transformacions i interrelacions amb l'Anthropozän, veiem que es tracten igual sobre les bases socials.

La pràctica de l'ensenyament-aprenentatge en l'Anthropozän no s'hauria d'ubicar únicament en les humanitats, sinó que requereix d'una didàctica de la història que es comprengui en si mateixa com una ciència que es responsabilitza i que forma i promou la competència anthropogener Reflexivität (Hübner, 2019).

L'Anthropozän, per tant, requereix d'una reflexió en la configuració del temps, l'espai, els actors, la matèria i l'epistemologia. Es tracta, doncs, de canviar l'enfocament de l'ésser humà com a centre de la història en l'ensenyament, i d'observar-lo com un agent més. D'aquesta manera, s'iniciaria una nova perspectiva amb l'objectiu de formar la competència anthropogener Reflexivität. 
A continuació, el debat va seguir amb les aportacions de Rein (2019), qui va estructurar tot el discurs al voltant de la pregunta: com pot ajudar la didàctica de la història en el desenvolupament d'estudiants crítics amb l'entorn i autònoms en els judicis de valors? L'autora intenta respondre-hi a través d'Ambiguitätstoleranz. El concepte d'«ambigüitat» el defineix com la competència per poder lidiar amb Widersprüchlichkeiten [contradiccions]. Unes contradiccions a l'interior de la mateixa societat que es poden equilibrar amb el jo i amb la identitat mitjançant la tolerància, tot fomentant així el pensament crític i l'acceptació entre els ciutadans. Una responsabilitat que recau sobre la didàctica de la història. Aspecte que, en aquest context i d'acord amb les definicions de Kühberger i Sedmak (2007), entenem com a: qui està implicat? quin paper tenen? per a què? per a qui són responsables? Així doncs, la didàctica de la història és responsable per ella mateixa i per als estudiants, i està subjecta a unes normes basades en les ciències històriques. Per tant, els objectius en els aprenentatges històrics -inclosa la promoció de diverses competències en l'alumnat - són, per una banda, desenvolupar el pensament crític i, per l'altra, afavorir l'orientació en el present. Finalitats directament relacionades amb la construcció d'una identitat.

Finalment, trobem les aportacions de Kocka (2019), qui veu en la didàctica de la història una de les disciplines que més s'ocupa de les responsabilitats socials, ja que s'interessa pel qui, pel què, pel de qui, pel quan, per l'on, pel com, per l'en què i pel per què. Preguntes que no es fan en la ciència ni en la investigació, ni en les teories històriques.

Des dels anys 70, la didàctica de la història ha contribuït de forma exponencial a l'aula i a l'escolaritat. Una declaració que es confirma en la rellevància i en la responsabilitat socials que ha tingut. Alguns exemples d'aquests fets són: la integració de discursos d'investigacions històriques; I'inici de canvis significatius en els mètodes d'ensenyamentaprenentatge; la formació del professorat, i la creació de materials didàctics.

No obstant, avui dia la didàctica de la història encara té diverses responsabilitats socials, i així ho manifesten els currículums dels diversos Landes d'Alemanya. El seu objectiu principal és «des mündigen in der Gesellschaft verantwortungsbewusst handelnden Bürgers beizutragen» (p. 2) [contribuir a la formació de ciutadans responsables (majors d'edat, segons Kant)] que actuïn de manera responsable en la societat]. Una altra de les seves finalitats és crear una consciència històrica (auto)reflexiva en els estudiants, que els permeti actuar de forma autònoma i crítica.

Per tant, la didàctica de la història té les següents responsabilitats: 1) lluitar contra l'escepticisme envers la democràcia; 2) evitar el nacionalisme; 3) treballar conjuntament $a m b$ les investigacions d'història i de ciències teòriques de la història; 4) ensenyar des d'una perspectiva global, oposada a la docència nacionalista, racista, antisemita i homòfoba; 5) promoure la multiculturalitat a l'aula, i 6) treballar amb la digital literacy, l'objectiu de la qual és utilitzar els mitjans de comunicació de manera crítica.

\section{Panell III. Quines són les tasques sociopolítiques de la didàctica de la història I?}

El tercer panell es va estructurar entorn de les propostes de Jörg van Norden (Unsicherheit und Verantwortung - Koordinaten einer 'emanzipatorischen' Geschichtsdidaktik?), Lale 
Yıldırım (Didaktik der Geschichte zwischen Ohnmacht und Verantwortung), i Melanie Noesen i Mike Richartz (Geschichte als allgemeindidaktisches Werkzeug zur Konstruktion des persönlichen historischen Raums).

El debat s'inicià amb les aportacions de van Norden (2019), qui planteja si la història ha de crear o ha de destruir inseguretats. Segons l'autor, aquesta qüestió sempre sorgeix en períodes de crisi, en els quals es remarquen les continuïtats i les tradicions d'una societat i d'una política de l'estat. La Geschichtskultur — cultura històrica- segueix aquest principi (un exemple d'això és el camí de Sant Jaume). Van Norden (2019) veu la narrativa tradicional de Rüsen com la narrativa històrica d'una Kontingenzbewältigung. De fet, la contingència remet en llatí a la casualitat, a la possibilitat, i es refereix a la incertesa en l'experiència de les persones durant la vida. La narració és una construcció i la responsabilitat del contingut depèn del narrador. Així mateix, crea llaços entre el present i el passat perquè l'ara no dona res amb què poder eliminar o evitar les incerteses o els riscos.

Van Norden (2019) veu la responsabilitat com Rede und Antwort zu stehen, és a dir, donar respostes i justificacions de per què un fet es narra d'una forma i no d'una altra. Per tant, la Geschichtskultur té una gran responsabilitat envers la societat.

Comprendre la narració històrica permet donar significació al no significat, realitzar una crítica a les ideologies i fomentar una emancipació de diferents pensaments.

Seguidament, Yıldırım (2019) presentà les conseqüències per a la didàctica de la història de la resolució del VHD del 27 de setembre de $2018^{3}$. Aquesta disciplina — que forma part de la ciència de la història i l'objecte d'interès de la qual es centra en la consciència històrica d'una societat i, per consegüent, d'una societat de migració- hauria de posicionar-se clarament davant de la resolució del VHD. L'alumnat hauria de formar-se a través de l'experiència del temps i vèncer les contingències temporals mitjançant un pensament històric. L'aprenentatge històric des d'una perspectiva rousseauniana dona un sentit a les experiències que es realitzen amb el temps per poder-se moure en un «riu de temps» (Yıldırım, 2019).

Així mateix, seguint la línia de l'escola de Frankfurt, s'ha de realitzar una crítica a les ideologies que persisteixen en l'educació històrica i política — vistes per l'autora com quelcom homogeni-, per fomentar l'emancipació de la didàctica de la història. En conseqüència, es tracta de no ubicar-se únicament en el «riu temporal», sinó de ser un mateix en un riu i d'explicar per què han tingut més èxit unes interpretacions que d'altres (Yıldırım, 2019). Revisant, així, la significació històrica dels esdeveniments nacionals que es realitzarà a partir de quatre punts: 1) no es comprendrà l'educació històrica com a educació historicopolítica. S'ha de reflexionar en la pròpia identificació ideològica i política; 2) la diversitat s'ha de reglamentar des de les altes institucions; 3) les construccions d'identitat es delimiten en la diversitat. És possible narrar i reflexionar sobre una pròpia

(3) El VHD, «Verband der Historiker und Historikerinnen in Deutschland», és una unió dels historiadors a Alemanya en què els participants van firmar el seu deure de resistir contra les tendències no-democràtiques que actualment existeixen en aquell país. La resolució especifica el següent: «Historiography as a scholarly discipline has the task of analyzing historical developments in order to contribute to a better understanding of contemporary issues and to explore the complexity of their causes. Given that politics seems to be increasingly driven by the volatility of public opinion polls and ever faster-paces media dynamics, we would like to stress that only thinking in longer-range time periods can guarantee the future of our political system in the long run» (VHD, 2018). 
identitat, però no ho és interrelacionar l'auto-narració amb la cultura dominant i comprendre's i reflexionar-se com una societat d'immigració, i 4) un mateix ha de ser el «riu de temps» i utilitzar les contingències com a base i potencial per actuar. L'orientació ha de ser reflexionada dintre de la diversitat.

Per finalitzar el panell III trobem les aportacions de Noesen i Richartz (2019). Els autors es centren en el procés d'ensenyament-aprenentatge, en el qual ubiquen la història com Meta-Werkzeug, és a dir, com una eina, mentre que la didàctica de la història adquireix el rol principal. Un objectiu d'aquesta disciplina és generar un procés d'autonomia entre l'alumnat i formar, així, una identitat pròpia amb la qual es poden reinterpretar situacions de l'aprenentatge. La història és una eina per a la comprensió dels seus propis actes i fets, un mitjà entre l'individu i el col-lectiu.

Aquests dos autors defineixen la didàctica de la història com un traductor de la narrativa de la història, que treballa la identitat i la responsabilitat social. Els discursos antidemocràtics i racistes de la primera meitat del segle XX s'haurien de debatre a partir de les seves estructures. Per tant, hauria de crear-se un pensament multiperspectiu. Per ferho es necessita una consciència continua i osmòtica de construcció de la mateixa visió, en què s'intenten ubicar, a l'aula, els fets viscuts per un col-lectiu i pensar de forma multiperspectiva. Com exposen Noesen i Richartz (2019), «Das Bewusstsein der Historizität des "Zu-Lernenden", ist eine grundlegende Voraussetzung der Wirklichkeits-und Aktualitätsbindung von Bildungsinhalten und Kompetenzen» (p. 3). [La consciència de la historicitat de l' «alumne que ha d'aprendre» és un requisit previ fonamental per a la realitat i l'actualitat dels continguts i les competències de l'educació].

Aquesta historicitat ha d'aparèixer com a base fonamental a l'escola i a l'aula per garantir les estructures democràtiques de la nostra societat. Els docents del futur seran els traductors per construir aquesta consciència històrica i per poder iniciar en l'alumnat: 1) una discussió de la seva pròpia biografia d'aprenentatge i la seva reconstrucció històrica, per donar-li una altra significació; 2) el reconeixement de la historicitat en els seus aprenentatges; 3) el desenvolupament d'una dimensió històrica dels continguts de l'aprenentatge escolar, i 4) la localització d'aquests contextos significatius, explicats i argumentats històricament, amb les seves perspectives subjectives.

Així doncs, es demostra la necessitat d'ubicar la història com una meta-eina per assolir-ne una comprensió profunda que entén l'aprenentatge també com una participació. «Sie dient somit der Grundlage der Bewusstwerdung gesellschaftlicher Verantwortung bei Lernenden und Lehrenden um, im Idealfall, zum (bewussten oder unbewussten) Ausgangspunkt von individuellen Handlungsprinzipien zu werden» (p. 4) [Per tant, serveix de base perquè l'alumnat i el professorat prenguin consciència de la responsabilitat social, a fi que, en el millor dels casos, es converteixi en el punt de partida (conscient o inconscient) dels principis individuals d'accióc.

\section{Panell IV. Quines són les tasques sociopolítiques de la didàctica de la història II?}

L'últim panell, corresponent a la segona part del panell II, està format per les propostes de Julia Thyroff i Martin Nitsche (Gesellschaftliches historisches Lernen als künftiges Feld der 
Geschichtsdidaktik) i d'Oliver Plessow (Historisches Lernen im Zeitalter von Geschichtsrevisionismus und Alternative Facts? Konstruktivität, Narrativität und Perspektivität als Herausforderungen für historisch-politisches Lernen).

El tema central de Thyroff i Nitsche (2019) és de quina manera la didàctica de la història pot combatre les polítiques extremes que abusen de la història. Aquests autors veuen en l'aprenentatge històric una possibilitat per frenar aquest abús. La significació social del passat és una qüestió objecte de debat des de fa anys sota el concepte de Geschichtskultur. Les anàlisis i les teories de les narratives s'han basat en tres àmbits: les dimensions, les funcions i els actors (Demantowsky, 2018, citat a Thyroff i Nitsche, 2019). Una visió que només té en compte l'individu, denotant-se una carència en l'aprenentatge històric a partir del col-lectiu (Thyroff i Nitsche, 2019). I per trencar aquesta barrera entre individu i col-lectiu, Thyroff i Nitsche (2019) plantegen una adaptació de la proposta d'acció humana d'Engeström (1999), considerant que:

- el coneixement construït a través de la significació es manifesta en un sistema de signes i lletres.

- la interacció entre persones es produeix mitjançant l'ús d'aquest sistema.

- la relació i connexió entre els subjectes i objectes esdevenen a través de l'acció social i històrica.

Els canvis socials, com exposen Thyroff i Nitsche (2019), succeeixen a través de les tensions entre l'objecte (naturalesa), els humans i els dilemes científics. Tensions que es solucionen mitjançant les accions i els recursos regressius anteriors o durch die Entwicklung neuer gesellschaftliche Tätigkeiten [pel desenvolupament de noves accions socials].

I això es comprèn com aprenentatge històric.

Si adaptem, doncs, els plantejaments de la teoria d'Engeström a la didàctica de la història, la imatge i l'estructura que es representen són les persones (subjectes) a través del pensament històric; i utilitzant les mesures de la història (fonts històriques, mapes, etc.), s'adapten a - (de) i (re)construeixen— la història.

Durant aquest procés, determinant pel reconeixement o el refús de la història, es consideren les necessitats i funcions humanes - com l'antropologia (cognició, emoció, política) social (utilitat, identificació) — per a l'ús de les mesures històriques. Quan no es pot resoldre a través d'exemples o d'estructures existents, es desenvolupen més dilemes. Causant, d'aquesta manera, nous paradigmes de l'acció històrica cultural o canvis més relatius o profunds (noves narratives). En aquest cas, podríem parlar d'un aprenentatge històric social comú.

Per últim, trobem les aportacions de Plessow (2019), qui parla de les tendències ètniques i homogènies en la política. Polítiques que curiosament neixen de votacions democràtiques i que, a vegades, els propagadors opinen que existeix un complex entre política, economia i ciència que té com a objectius malmetre i amagar les veritats del seu poble etnopluralista. Així, apareixen dues expressions d'un populisme tradicional i retrospectiu — Geschichtsrevisionismus i Alternative Facts - format per tres factors constitutius: 1) la sensació d'estar en desavantatge respecte d'altres grups (economia); 2) la por de perdre la seva identitat per una amenaça com la immigració (cultura), i 3) la tornada a un estat nació que ho reguli tot (política). 
La didàctica de la història ha de contribuir a la formació d'una consciència històrica que combati aquesta tendència i s'ha d'oposar totalment a la Geschichtsrevisionismus. Els atacs del constructivisme a les veritats en què la història, durant molt temps, basava les seves narratives implica, segons l'autor, que aquesta retrocedeixi en les seves produccions textuals. Això genera el perill de caure en una trampa del relativisme. És un mateix qui ha de comprovar el consens de les narracions amb les fonts històriques del passat. Aquest debat està a l'ordre del dia i ens fa plantejar si les competències i els recursos que donem a l'alumnat són suficients per combatre aquestes tendències.

La didàctica de la història té, així, dos camins d'acció: per una banda, un Aufklärungsdiskurs que potencia el pensament crític i històric dels estudiants i, per l'altra, comprovar els recursos d'una narrativa més estètica i experimental, analitzant aquelles discriminatòries i nacionalistes.

\section{Reflexions del 'Geschichtsdidaktik und gesellschaftliche Verant- wortung'}

La didàctica de la història té una gran responsabilitat social, atès que s'ocupa de formar en valors democràtics als futurs ciutadans d'una regió. La història, I'alumnat i el professorat són alguns dels agents més significatius del procés d'ensenyament-aprenentatge. No obstant, en els transcurs dels anys s'ha denotat una certa desafecció dels estudiants cap a aquesta disciplina. Buck (2019) cerca, simultàniament, les causes de la insensibilitat entre la història i els alumnes i la manera de recuperar o reconstruir aquesta ruptura. L'autor reconeix el vincle personal i emocional entre les persones i la història. Per tant, no només parlem de fets factuals i d'aprenentatge memorístic.

Aquestes qüestions adquireixen una perspectiva més filosòfica i antropològica amb McLean (2019), qui — seguint la línia de Kant— veu la interdisciplinarietat possible de la didàctica de la història amb la filosofia i, sobretot, amb la necessitat de generar una definició interdisciplinar. Si l'individu o la disciplina no arriben a la majoria d'edat, no poden responsabilitzar-se per ells mateixos i, ni molt menys, per la societat de la qual són dependents. Plató diria que seguim en la cova. D'aquesta manera, és necessari formar i fomentar la capacitat de reflexió per tal d'arribar a la majoria d'edat sent lliures i responsables. Una visió teòrica i filosòfica de les mancances de la societat actual.

Si examinem una visió més concreta de les problemàtiques d'aula, observem les dues dicotomies expressades per Zech (2019), qui analitza la identitat, el pluralisme i la tolerància enfront dels nacionalismes i radicalismes. La didàctica de la història té la responsabilitat social de fomentar el desenvolupament d'un alumnat crític, plural i tolerant. Però què és allò verídic que hem d'aprendre o ensenyar? La didàctica ha de potenciar la construcció de capacitats crítiques per part dels estudiants (Plessow, 2019; Rein, 2019; Thyroff i Nitsche, 2019; Yıldırım, 2019), com l'Anthropozän de Hübner (2019). Una manera de realitzar-ho és mitjançant l'anàlisi de les narratives que conformen la nostra identitat (Van Norden, 2019), per tal de combatre diversos problemes actuals com el neonacionalisme, l'escepticisme envers la democràcia, les fake news, els abusos de la història, entre d'altres.

Una solució podria ser treballar la història des d'una perspectiva global (Kocka, 2019) i múltiple (Noesen i Richartz, 2019). Hübner (2019) va més enllà i parla de la necessitat de connectar la naturalesa i la humanitat. Els éssers humans tenim una responsabilitat amb 
el món i depenem dels animals, la naturalesa, el clima, el medi ambient, entre altres aspectes. Fet que ocasiona el replantejament de la visió actual de l'aprenentatge històric.

\section{Paraules finals: nous reptes per a la didàctica de la història a Espanya}

En el transcurs de l'article hem presentat diverses teories sobre la responsabilitat de la didàctica de la història envers la societat. Un debat que està present des dels anys 90 i que es centrava en la categoria de la consciència històrica. Aquesta es va redefinir com a competència subjectiva del pensament històric i com a objecte de coneixement en la història de l'acció social, concebuda com la consciència del temps (Von Staehr, 1998). La consciència històrica entesa com a element fonamental del pensament històric és definida per Gómez, Ortuño i Molina (2014) com «la capacitat per interrelacionar fenòmens del passat i del present, desenvolupant la noció que tot present té el seu origen en el passat» (p. 10). Teories molt influïdes per les aportacions de Rüsen, qui considera que l'ensenyament de la història ha de fomentar principalment la construcció de l'autoconsciència històrica (López-Facal, 2014). Tendència que s'ha adherit al camp de la didàctica a Portugal i a Brasil.

Així doncs, la historiografia alemanya ha profunditzat molt sobre la consciència històrica en el pensament històric $i$, per consegüent, sobre les responsabilitats que té la didàctica de la història envers la societat. Reflexions que haurien d'actualitzar-se en la didàctica a Espanya, atesa l'aparició d'una nova realitat social amb nombrosos problemes identitaris. Domínguez (2002) va elaborar un seguit de reflexions per fomentar la comprensió de comunitats axiològicament complexes i entendre, així, el nou mapa mundial. Aportacions que han de replantejar-se, ja que s'ha originat un nou paradigma social que obliga a la didàctica de la història a pensar sobre les responsabilitats que té en la societat. I, d'aquesta manera, poder fer front a la crisi identitària dels últims anys amb l'expansió del nacionalisme per la Península.

\section{Referències}

Buck, T.M. (2019) "Veränderung" und "Veränderbarkeit": Geschichte als Gegenwarts-und Handlungswissenschaft. Fünfter Workshop des Arbeitskreises, Geschichtsdidaktik theoretisch". 11.-12. 3. 2019, Universität zu Köln.

Chakrabarty, D. (2011) «Verändert der Klimawandel die Geschichtsschreibung?». Transit Europäische Reve, 41, pp. 143-163.

Domínguez, C. (2002) «La enseñanza de la Historia: identidad cultural y valores democráticos en una sociedad plural». Revista de Teoría y didáctica de las Ciencias Sociales, (7). Recuperat de https://www.redalyc.org/html/652/65200705/

Gómez, C., Ortuño, J. i Molina, S. (2014) «Aprender a pensar históricamente. Retos para la historia en el siglo XX|». Revista Tempo e Argumento, Florianópolis, v. 6, n.11, p. 05-27. Recuperat de http://dx.doi.org/10.5965/2175180306112014005

Hübner, A. (2019) Das Anthropozän unterrichten? Zur Diskussion um die gesellschaftliche Verantwortung der Geschichtsdidaktik. Fünfter Workshop des Arbeitskreises "Geschichtsdidaktik theoretisch". 11.-12. 3. 2019, Universität zu Köln. 
Kocka, U. (2019) Was sind gesellschaftliche Aufgaben der Geschichtsdidaktik?. Fünfter Workshop des Arbeitskreises "Geschichtsdidaktik theoretisch". 11.-12. 3. 2019, Universität zu Köln.

Kühberger, C. i Sedmak, C. (2007) «Die Verantwortung der Historikerinnen und Historiker - Systematische Überlegungen zu einem Teilbereich einer Ethik der Geschichtswissenschaft». En Künberger, C. et al. Wahre Geschichte - Geschichte als Ware. Die Verantwortung der historischen Forschung für Wissenschaft und Gesellschaft. Rahden (Westf.), Verlag Marie Leidorf, p. 1-26.

López Facal, R. (2014) «La LOMCE y la competencia histórica». Ayer: Revista de Historia Contemporánea, 94(2). Recuperat de http://www.ub.edu/histodidactica/images/documentos/pdf/Lopez\%20Facal\%20Ay er\%2094.pdf

McLean, P. (2019) Die Verantwortung der Geschichtsdidaktik für eine mündigkeitsorientierte (historische) Bildung. Fünfter Workshop des Arbeitskreises "Geschichtsdidaktik theoretisch". 11.-12. 3. 2019, Universität zu Köln.

Noesen, M. i Richartz, M. (2019) Geschichte als allgemeindidaktisches Werkzeug zur Konstruktion des persönlichen historischen Raums. Fünfter Workshop des Arbeitskreises „Geschichtsdidaktik theoretisch“. 11.-12. 3. 2019, Universität zu Köln.

Plessow, O. (2019) Historisches Lernen im Zeitalter von Geschichtsrevisionismus und Alternative Facts? Konstruktivität, Narrativität und Perspektivität als Herausforderungen für historisch-politisches Lernen. Fünfter Workshop des Arbeitskreises "Geschichtsdidaktik theoretisch". 11.-12. 3. 2019, Universität zu Köln.

Rein, F. (2019) Ambiguitätstoleranz als Ziel?! Zur Verantwortung der Geschichtsdidaktik. Fünfter Workshop des Arbeitskreises "Geschichtsdidaktik theoretisch". 11.-12. 3. 2019, Universität zu Köln.

Thyroff, J., i Nitsche, M. (2019) Gesellschaftliches historisches Lernen als künftiges Feld der Geschichtsdidaktik. Fünfter Workshop des Arbeitskreises "Geschichtsdidaktik theoretisch". 11.-12. 3. 2019, Universität zu Köln.

Van Norden, J. (2019) Unsicherheit und Verantwortung - Koordinaten einer 'emanzipatorischen' Geschichtsdidaktik?". Fünfter Workshop des Arbeitskreises "Geschichtsdidaktik theoretisch". 11.-12. 3. 2019, Universität zu Köln.

VHD (2018) Resolution of the Association of German Historians (VHD, Verband der Historiker und Historikerinnen Deutschlands) on Current Threats to Democracy. Recuperat de https://www.historikerverband.de//verband/stellungnahmen/resolution-oncurrent-threats-to-democracy.html\#c1553

Von Staehr, G. (1998) «Didáctica de la Historia y enseñanza de la Historia en la Alemania unificada». Con-ciencia social: anuario de didáctica de la geografía, la historia y las ciencias sociales, (2), p. 133-148.

Yıldırım, L. (2019) Didaktik der Geschichte zwischen Ohnmacht und Verantwortung. Fünfter Workshop des Arbeitskreises "Geschichtsdidaktik theoretisch". 11.-12. 3. 2019, Universität zu Köln.

Zech, M. (2019) Welchem didaktischen Konzept folgt der Geschichtsunterricht? Fünf Thesen. Fünfter Workshop des Arbeitskreises "Geschichtsdidaktik theoretisch". 11.-12. 3. 2019, Universität zu Köln. 

nes del grupo de trabajo Geschichtsdidaktik theoretisch Arbeitskreis der Konferenz für Geschichtsdidaktik e.V

Resumen: El paso del siglo XX al XXI ha promovido, especialmente en las últimas décadas, un cambio social remarcable. La crisis económica y sociopolítica, el cambio climático, la inmigración, las guerras, el neonacionalismo, entre otros, son a la vez aspectos políticos y educativos. La didáctica de la historia tiene que hacer frente a estos nuevos retos y debe responsabilizarse como disciplina científica. En el artículo se resumen los debates epistemológicos que llevaron a cabo el grupo de trabajo Geschichtsdidaktik theoretisch Arbeitskreis der Konferenz für Geschichtsdidaktik eV en marzo de 2019. En esta reunión varios científicos del ámbito expusieron sus perspectivas con relaión a este nuevo paradigma de las responsabilidades sociales de la didáctica de la historia. Retos que han llegado a España más tarde, pero que constituyen algunos de los principales núcleos de conflicto en la actualidad.

Palabras clave: Didáctica de la historia, conciencia histórica, sociedad, responsbailidad social.

\section{Les nouveaux paradigmes de la didactique de l'histoire en Allemagne : réflexions du groupe de travail Geschichtsdidaktik theoretisch Arbeitskreis der Konferenz für Geschichtsdidaktik e.V}

Résumé: Le passage du XXe au XXle siècle a favorisé, notamment ces dernières décennies, un changement social remarquable. La crise économique et sociopolitique, le changement climatique, l'immigration, les guerres, le néonationalisme, entre autres, sont des aspects à la fois politiques et éducatifs. La didactique de I'histoire doit faire face à ces nouveaux défis et doit se responsabiliser en tant que discipline scientifique. Dans cet article, nous résumons les débats épistémologiques menés par le groupe de travail Geschichtsdidaktik theoretisch Arbeitskreis der Konferenz für Geschichtsdidaktik e.V en mars 2019, au cours desquels divers scientifiques de ce domaine ont exposé leurs perspectives en rapport avec ce nouveau paradigme des responsabilités sociales de la didactique de l'histoire. En Espagne, ces défis sont arrivés plus tard, mais ils s'avèrent être au cœur des principaux conflits actuels.

Mots clés: Didactique de l'histoire, conscience historique, société, responsabilité sociale.

\section{The new paradigms of teaching history in Germany: the reflections of the working group Geschichtsdidaktik theoretisch Arbeitskreis der Konferenz für Geschichtsdidaktik e.V}

Abstract: The transition from the twentieth to the twenty-first century has promoted remarkable social change, especially in recent decades. The economic and socio-political crisis, climate change, immigration, wars, neonationalism, among others, are both political and educational aspects. Teaching history must meet these new challenges and take responsibility as a scientific discipline. In the article we summarize the epistemological debates carried out by the working group Geschichtsdidaktik theoretisch Arbeitskreis der Konferenz für Geschichtsdidaktik eV in March 2019. In these debates, several scientists in the field presented their perspectives on this new paradigm of the social responsibilities of teaching history. These challenges have come to Spain later, but that are still some of the main nuclei of conflict today.

Keywords: Didactics of history, historical awareness, society, social responsibility. 